\author{
ARTUR JACEK JĘDRZEJEWICZ \\ (D) https://orcid.org/0000-0003-0858-3194 \\ Uniwersytet Przyrodniczo-Humanistyczny w Siedlcach \\ Siedlce
}

\title{
Tematyka migracyjna na przykładzie filmu Der Junge Siyar / Before snowfall kurdyjskiego autora Hishama Zamana
}

\begin{abstract}
Migration themes using the example of Der Junge Siyar/ Before snowfall, a film by the Kurdish author Hisham Zaman
\end{abstract}

\begin{abstract}
The paper is an attempt to highlight the importance of cultural texts created by authors from contemporary migration circles. There are several reasons for their relevance: without resorting to stereotypes, clichés and intermediations, using the original author's language, they show traumatic experiences (Grenzsituationen) and testimonies; in the narratological sense, they combine the message of traditional oral culture with a contemporary author's text of culture, making it possible to understand contents which are elusive for journalistic forms and the restrictions imposed on new media. It also describes the emergence of the refugee story sub-genre at the beginning of the $21^{\text {st }}$ century and the Polish culture in relation to this phenomenon.
\end{abstract}

Keywords: text of culture, migrations, narratology, author

Dyskusje na tematy migracji, którą generuje konflikt w Syrii, polityczni demagogowie polaryzuja w rozmaitość grup problemowych, jednak finalnie odcinają się od zrozumienia przeżyć konkretnych ludzi: uchodźców czy imigrantów. A ich doświadczenia to często skrajnie dramatyczne przė̇ycia, traumy (sytuacje graniczne) ${ }^{1}$. Imigranci, którzy z narażeniem życia i zdrowia zmuszeni są walczyć o osobistą wolność i godność, przekraczają granice nie tylko państwowe i polityczne, ale też kulturowe, obyczajowe, etyczne. Aby zrozumieć miałkość debat na tematy migracyjne w europejskiej i polskiej

1 W sensie bliższym typologii K. Jaspersa (Grenssituationen) (1990) niż A. Maslowa (Peak experience) (1986). 
przestrzeni publicznej, wystarczy przywołać niezwykły obraz Kurda Hishama Zamana ${ }^{2}$. For snøen faller (tytuł w jęz. norweskim) to tekst kultury zasługujący na głębsze analizy przeprowadzone przez badaczy w rozmaitych obszarach nauk humanistycznych (filmoznawców i literaturoznawców, językoznawców i kulturoznawców, etnologów, etyków i filozofów, socjologów i politologów, psychologów czy wreszcie specjalistów w zakresie bezpieczeństwa wewnętrznego i międzynarodowego) - w szczególności tych podzielających pogląd, że migrują nie tylko ludzie, ale i pojęcia (Bal 2012).

\section{Narratologia instrukcji}

Ten współczesny dramat, road movie, uchodźczą odyseję, etnograficzną przypowieść a zarazem paradokumentalne świadectwo można genologicznie określić jako nowy podgatunek: refugee story. Film rozpoczyna się od bezdialogowej sceny, ukazującej w jaki sposób możliwe jest nielegalne przekroczenie granicy tureckiej z Kurdystanu (z Iraku zamieszkiwanego przez diasporę kurdyjska). Otóż bohater o imieniu Siyar (Abdullah Taher), młodzieniec z tradycyjnie „wysypującym” się wąsem, jaki musi w tym kręgu kulturowym nosić mężczyzna, zostaje „zafoliowany” - owinięty szeroka folią przemysłową stosowaną w transporcie towarów.

Obrazy są podane niezwykle bezpośrednio, w sposób autentyczny, zaś forma - dzięki rejestracji kadrów w stylu reporterskim, z częstym wykorzystaniem kamery ruchomej - przypomina dokument (autorem zdjęć jest Marius Matzow Gulbrandsen ${ }^{3}$.

W czasie kolejnego etapu podróży niezbędne jest rozerwanie folii i utworzenie małego otworu na usta, aby bohater mógł oddychać i przeżyć transport, oraz wetknięcie mu starych gogli, które mają chronić oczy. Następnie młody Siyar zostaje umieszczony w cysternie do przewozu ropy naftowej, w której za wszelką cenę musi (za pomocą łańcucha) utrzymać się nad powierzchnią czarnej, tłustej mazi, w przeciwnym razie zginie.

2 Film jest koprodukcją Norwegii, Niemiec i Kurdystanu. Na świecie prezentowany był w trzech wersjach językowych: norweskiej, niemieckiej, angielskiej. Tytuł w jęz. norweskim: For snoen faller, w jęz. niemieckim: Der Junge Siyar, w jęz. angielskim: Before snowfall. Film [tytuły w jęz. polskim: Zanim spadnie śnieg / Młody Siyar] nie był dystrybuowany w Polsce.

3 Marius Matzow Gulbrandsen jest absolwentem PWSFTviT w Lodzi. Zob. Nors filminstitutt (Norweski Instytut Filmowy), http://minside.nfi.no/96676/everything-will-be-ok [dostęp: 08.11.2019]. 
Wzięli więc Jeremiasza i wtrącili go, spuszczając na linach, do cysterny (...). W cysternie zaś nie było wody, lecz błoto; zanurzył się więc Jeremiasz w błocie (Ks. Jeremiasza 38, 6) ${ }^{4}$.

Wprowadzenie w ekspozycję i sposób „opowiadania” tego teksu kultury jest konieczne, gdyż synopsis czy storyline nie oddadzą powagi dramatu.

Przemytnicy zapewniaja zatem transport i wstępne zabezpieczenie. Sam akt walki o życie zostawiaja „,towarowi”, który płatności dokonał przed wyjazdem. Utrzymać się ponad powierzchnią ropy, wewnątrz pełnej rozbełtanej mazi cysterny pędzącej po górzystym terenie, to prawie jak zostać dżinnem z Ksiegi tysiqca i jednej nocy czy innych perskich baśni. A to dopiero początek. Na granicy z Turcja okazuje się, że proces foliowania miał jeszcze inny cel. Gdy młody Kurd słyszy dźwięk otwierania włazu pojazdu i gdy jego wzrok oślepia snop światła, musi nabrać powietrza, zanurkować pod powierzchnię smolistej cieczy i czekać, aż kontrola graniczna sprawdzi cysternę. Kontrola jest skrupulatna, gdyż Kurdów nielegalnie przedostających się przez granicę traktuje się jak terrorystów (z organizacji PPK ${ }^{5}$ ). „Nielegalny Jonasz" w brzuchu stalowego Lewiatana (Księga Jonasza 2, 1-11) czeka na szarpnięcie pojazdu oznaczające wjazd na teren Turcji. Skojarzenia i ewokacje biblijne $-z$ Jeremiaszem i Jonaszem - sa oczywiste, bo Orient to naturalny archetyp: nie ma w nim opowieści bez przypowieści, bez symboli czy odwołań do mitu.

W sensie narratologicznym, mimo że kurdyjski autor zdobył dyplom reżyserski ${ }^{6} \mathrm{w}$ Europie, przekaz nie jest przesadnie wyrafinowany i nie zniekształca (sztucznie) opowieści postmodernistycznymi naleciałościami. Twórca nie naśladuje eksperymentatorów literackich (J. Joyce’a czy J. Cortázara) ni filmowych (J.L. Godarda i La Nouvelle Vague czy A. Resnaisa i A. Robbe-Grilleta z kręgu nouveau roman ${ }^{7}$ ). Wybiera prostotę, więc po realizmie paradokumentalnym wprowadza retrospekcje o charakterze etnokulturowym i obiektywnie przedstawia tradycyjne środowisko Kurdów. W konsekwencji tego założenia, po dramatycznym wstępie, niespieszna narracja prowadzi do kolejnych odkryć, a zarazem zaskakujących faktów z życia patriarchalnej,

\footnotetext{
4 Pismo Święte Starego i Nowego Testamentu 1971, 950-951.

5 „Partia Pracujących Kurdystanu” uważana jest przez władze Turcji za organizację terrorystyczna.

${ }^{6}$ Hisham Zaman ukończył Den Norske Filmskolen w Lillehammer w Norwegii.

${ }^{7}$ Chodzi o autorów tekstu i obrazu Zeszłego roku w Marienbadzie (L'Année dernière à Marienbad) z roku 1961.
} 
kurdyjskiej społeczności. Otóż zaczynamy rozumieć, iż młody Kurd wcale nie chce być imigrantem. Nie chce dostać się do Europy, aby zarabiać, zabijać niewiernych czy dołączyć do licznej rodziny pobierającej tam social benefit. Nasz bohater ma tylko jeden cel i motyw. Ponieważ wkrótce będzie głowa klanu, musi zmyć hańbę, która - według wielowiekowych rytów - sprowadziła na rodzinę jego starsza siostra Nermin (Bahar Ozen). Siyar musi ją odnaleźć, a następnie wymierzyć karę za ucieczkę przed ślubem z o wiele starszym, bogatym mężczyzną z innego klanu, którego wybrał dla niej ojciec. Rodzina niedoszłego pana młodego poczuła się upokorzona. Hańbę tę zmyje jedynie śmierć Nermin, ale ona uciekła daleko, gdzieś na północ Europy.

\section{Orient - Stambuł}

Młody Kurd musi dostać się do Norwegii i nielegalnie pokonać odległość kilku tysięcy kilometrów. Na poziomie przypowieści jego droga będzie jeszcze dłuższa... Pierwszym etapem jest Stambuł. Piękny Konstantynopol: opisywane od wieków miasto potężnych bazylik chrześcijańskich przekształconych w meczety o strzelistych minaretach. To nie miasto, ale „sens życia”, jak napisał w swych powieściach O. Pamuk (2003), podobnie opiewal to miejsce przypomniany przez tureckiego noblistę A.H. Tanpinar (Spokojny umyst, 2013). Stambuł nie został wybrany przez Siyara z powodów kulturalnych, historycznych czy estetycznych, lecz dlatego, że jest to stolica wszystkich pragnących przebyć droge ,z Orientu” do Europy, ponieważ drugi brzeg wiekowego molocha to przecież już jej wrota. Tu zatem mają swoje bazy liczne międzynarodowe „firmy” trudniące się przemytem ludzi. Sposobów przedostania się do Niemiec, a konkretnie do Berlina - który z kurdyjskiej perspektywy jest przedsionkiem Norwegii - jest wiele: droga lądowa, morska i lotnicza. Tak przynajmniej zapewniają ludzie, którzy za ustaloną opłata moga „pomóc” w pokonaniu tej trasy. Siyar ma ograniczone środki finansowe, ale bez ekspiacyjnego oba rody aktu nie ma po co wracać w rodzinne strony. Akcja pozornie utyka nad Bosforem, ale autor kongenialnie wprowadza tu klasyczną retardację w celu odmalowania uchodźczego środowiska i postawienia na drodze Siyara młodziutkiej imigrantki o imieniu Evin (Suzan Ilir).

Film Kurda, tworzącego swoje opowieści w Europie, ewokuje przekaz (tak na poziomie racjonalnym, jak i intuitywnym), że korzenie czy geny kul- 
turowe tradycji, z której się wywodzi, cenią „opowiadanie” oraz sam jego akt. Dlatego tekst kultury Hishama Zamana jest tak świeży - łączy bowiem w sobie tradycję i aktualność. Dla Kurdów „opowiadanie” zawsze stanowiło ważny element tożsamości i przetrwania kultury oralnej, bogatej tradycji przekazu ustnego, gdyż wyniszczani przez Turków i Persów - nie mogli mieć swoich bibliotek. Mocną stroną wspomnianego opowiadania jest również niejednoznaczny bohater, głęboko osadzony w tradycji, a zarazem paradoksalnie - niezwykle współczesny. Autor znakomicie orientuje się w poruszanej tematyce: od początku mamy poczucie, iż zna uchodźców, emigrantów podobnych do portretowanych; poznał ich „świadectwa”, osobiste przypadki i historie. I warto dodać, że młody Siyar spotyka „w drodze” cała plejadę barwnych postaci. Ich prezentacja jest również narracyjną siłą napędową For snoen faller.

Z kolei minusem filmów dokumentalnych - nagradzanych i komentowanych w ostatnich latach, a realizowanych w obozach dla uchodźców - Mediterranea (2015) czy Human Flow (2018) jest ich publicystyczny ciężar gatunkowy. Są nijakie, „ciagnące się” i ewokuja podejrzaną sztuczność quasi-dokumentalnych „ustawek”. Wydają się wspierać zakamuflowane organizacje polityczne i stanowić „dzieła” fundacji, dla których tego typu obrazy są potwierdzeniem, że warto dawać im pieniądze. Dodatkowo można im zarzucić tanią czułostkowość, a motywów ich powstania doszukiwać się w chęci zdobywania festiwalowych nagród.

$\mathrm{Na}$ poziomie kształtowania się wspomnianego podgatunku warto przypomnieć, iż kino o tematyce migracyjnej przecierało sobie w Europie zachodniej szlaki od pierwszych lat XXI wieku. Kiedy Polacy szykowali się do wejścia do UE, twórcy tacy jak Abdellatif Kechiche (obywatel francuski pochodzący z Tunezji) i nieco później Fatih Akın (obywatel Niemiec o korzeniach tureckich), których nazwiska uświetniają dziś festiwale w Cannes, Wenecji czy Berlinie, pisali już autorskie scenariusze i szukali europejskich producentów dla sfinansowania swoich obrazów. Kechiche już w 2000 roku zrealizował znakomity film Wina Woltera (La Faute à Voltaire), w którym sportretował paryskie środowisko uchodźców i imigrantów (z byłych francuskich kolonii) z kunsztem, jakiego nie powstydziłby się sam Honoré de Balzac. Zaś Głowa w mur Akına (Gegen die Wand) - oprócz uzyskania tytułu najlepszego filmu europejskiego w roku $2004^{8}$ - było głosem pokolenia tu-

\footnotetext{
8 Nagroda Europejskiej Akademii Filmowej za najlepszy obraz roku 2004 (European Films Academy Award).
} 
reckich imigrantów i inspiracją dla młodszych twórców wywodzących się z tego środowiska9. Pojawiły się także filmy o tematyce migracyjnej tworzone przez autorów skandynawskich, spośród których obraz Norwega Hansa Pettera Molanda The Beautiful Country (2004) wydaje się najwybitniejszy ${ }^{10}$. Kontynuatorem tej tradycji jest właśnie Hisham Zaman, gdyż wszystkie jego filmy fabularne (filmografia na końcu artykułu) traktują o współczesnych tematach związanych z diasporą kurdyjska, z migracjami oraz z ich wielokulturowymi konsekwencjami czy skutkami; z piętnem odciśniętym na bohaterach.

Czy w Polsce powinny lub moga powstawać teksty kultury tworzone przez filmowców ze współczesnych stref migracyjnych? Rozważmy tę kwestię à rebours: ponad trzydzieści lat temu Polacy byli imigrantami, uchodźcami politycznymi. Wystarczy przywołać dramat Emigranci napisany w roku 1974 przez Sławomira Mrożka - wówczas imigranta ${ }^{11}$ z Polski mieszkającego w wielu krajach (m.in. we Francji, USA czy Meksyku), aby odpowiedź stała się oczywista. Tekst ten jest dramatem scenicznym, jednak podobnie jak w obrazie Zamana czy w poezji i eseistyce tworzonej na emigracji przez Czesława Miłosza, siła świadectwa to siła autotematyzmu (Sandauer 1981, 443).

\section{Berlin - Oslo}

Nie wiadomo, czy autor filmu jest człowiekiem, który sam - na przykład w drodze na studia do Norwegii - przeżył, doświadczył podobnych trudów drogi jak młody Siyar, lecz z pewnością musiał wykonać drobiazgową do-

\footnotetext{
9 Interesującym autotematycznym tekstem kultury jest komediodramat reżyserki Yasemin Samdereli Almanya - Willkommen in Deutschland (2011), która zrealizowała go na kanwie doświadczeń rodziców i dziadków - tureckich imigrantów, tzw. „gastarbeiterów” przybyłych do pracy na zaproszenie rządu RFN w latach sześćdziesiątych XX w.

${ }^{10}$ Film opowiada historię wietnamskiego mężczyzny, który próbuje nielegalnie dostać się z Wietnamu (przez Chiny) do USA. W trakcie finalizacji tego tekstu media donosiły o śmierci 39 imigrantów z Azji. Zob. doniesienia z brytyjskiego dziennika The Sun, https://www.the sun.co.uk/news/10174799/essex-lorry-bodies-driver-newschinesearrest/?ut m_medium=Soc ial\&utm_campaign=sunmaintwitter\&utm_source=Twitter\#Echobox=1571909665 [dostęp: 08.11.2019].

11 Dramat był często wystawiany w „teatrze podziemnym” w latach 1975-1989. Znakomitej adaptacji tekstu Mrożka dokonał Kazimierz Kutz w spektaklu dla Teatru Telewizji (TVP 1995). W rolach głównych wystapili Marek Kondrat (jako AA) oraz Zbigniew Zamachowski (jako XX).
} 
kumentację, poznać i wysłuchać wielu świadectw uchodźców (bez pośredniczeń dziennikarskich, translatorskich, medialnych). Film sprawia wrażenie, iż reżyser podjął się jego realizacji po dogłębnym, osobistym doświadczeniu uczestnictwa ${ }^{12}$ w życiu współczesnych uchodźców i migrantów. Tylko pod takim warunkiem mógł skonstruować opowieść tak przekonująca, gdyż pozbawioną klisz ze skopiowanych i „,wklejonych” fragmentów (tekstów) kultury Zachodu, stereotypowych uproszczeń zalewających nowe media (Manovich 2006). Dlatego też ten artykuł ma po części formę eseistyczno-opowieściowa, gdyz - w moim przekonaniu - namysł analityczny i formy narracyjne mogą się wzajemnie odświeżać.

Obraz Der Junge Siyar/Before snowfall jest swego rodzaju instrukcja, a równocześnie (anty)instrukcja, jak (nie)łatwo przekracza się granice. Szczególnie te kulturowe, mentalne i wewnętrzne (Grenssituationen), skłaniające do osobistego rozwoju, do zmiany przekonań, postaw. Z tego powodu film Kurda to równocześnie dramat inicjacyjny, a nawet nawiązanie do najlepszych tradycji Bildungsroman (Defoe, Mann). Wiele scen jest intensywnych emocjonalnie. Przykład z terytorium Grecji (początek strefy Schengen): służby graniczne nie interesują się liczbą ludzi nielegalnie przekraczających ich granice, gdyż i tak nakazują im iść z Grecji „do Europy”. Zmuszaja ich jednak do rozebrania się do naga, aby poczuli się bezbronni, a następnie do wydania (zdrady) prowadzących ich przewodników-przemytników. Wiedza, iż nielegalni imigranci zrobią wszystko, aby iść dalej.

$\mathrm{Na}$ poziomie ontycznym reżyser opowiada historię człowieka, który sam w sobie jest nośnikiem „opowiadania” archetypicznego. Jego historia przypomina Odyseusza i Jonasza. Siyar jako bohater jest jak zwój, jak księga zwinięta (foliat i folia - sic.) i zawierająca narrację. Przecież w kręgu kulturowym, w którym żyje kurdyjska diaspora (Irak, Iran, Syria, Turcja), powstawały fundamenty cywilizacji piśmiennej, gdzie opowieści - narracje należały do skarbów ważniejszych niż złote lampy Aladynów i kindżały sułtanów.

Jest w obrazie Zamana inna cenna, bo uniwersalna, myśl. „Obcy” z odmiennej tradycji i kultury zawsze jest jej nośnikiem, tak więc wzbogaca zastaną kulturę (Bauman 2016). Doskonale wyraził to noblista Elias Canetti w Ocalonym jezyku (1985), w którym ukazał bogactwo kulturowe tak odbierane, jak i wnoszone do Europy przez diasporę żydowskich Sefardyjczyków.

Polska - jako przestrzeń kulturowa, polityczna i społeczna - aktualnie nie interesuje się historiami wnoszonymi przez uchodźców na tyle, aby je

\footnotetext{
12 Nie bezpodstawne jest porównywanie doświadczeń H. Zamana do metody „obserwacji uczestniczącej” (jawnej lub niejawnej), znanej z nauk społecznych, zob. Babbie 2003.
} 
wchłaniać i wyrażać poprzez teksty kultury. Prawdopodobnie jest to związane z opóźnieniami i zaniedbaniami z czasów PRL oraz nagląca potrzebą odbudowy ważnych tradycji regionalnych, własnych małych ojczyzn. Natomiast ważną i dostrzegalną przestrzenią inkluzywną i otwartą na imigrantów, na ,obcych”, są wszystkie poziomy polskiego szkolnictwa i edukacji.

Tekst ten nie wyczerpuje niezwykle rozwojowego i aktualnego tematu i może być zarysem większej rozprawy na temat refugee story. Warto na koniec odnotować, że jesienią 2019 roku Kurdowie znów „weszli na wojenną ścieżkę" z Turcja, a echa tych dramatycznych wydarzeń asocjują z trwająca od 2011 roku wojną w Syrii. Wojną która wygenerowała wielomilionową falę uchodźców. Należy się zatem spodziewać nowych uciekinierów z tego regionu, a tym samym kolejnych tekstów kultury.

Filmografia Hishama Zamana

Vinterland, 2007.

Before snowfall / Die Junge Siyar (org. For snoen faller), 2013.

Letter to the King (org. Brev til Konger), 2014.

Bibliografia

Babbie E., 2003, Badania spoteczne w praktyce, przeł. Betkiewicz W. i in., Warszawa.

Bal M., 1999, Narratology: Introduction to the Theory of Narrative, Toronto.

Bal M., 2012, Wédrujace pojecia w naukach bumanistycznych. Krótki przeewodnik, przeł. Bucholc M., Warszawa.

Bales K., 2019, Jednorazowi ludzie. Nowe niewolnictwo w gospodarce światowej, przeł. Dzierzgowska A., Gdańsk.

Balicki J., 2012, Imigranci i uchodźcy w Unii Europejskiej: bumanizacja polityki imigracyjnej i asylowej, Warszawa.

Bauman Z., 2016, Obcy u nassych driwi, Warszawa.

Canetti E., 1985, Ocalony jesyk. Historia pewnej młodości, przeł. Przybyłowska M., Warszawa.

Czapka E., 2006, Stereotyp uchodźcy, Olsztyn.

Jaspers K., 1990, Filozofia egzystencji. Wybór pism, przeł. Lachowska D., Wołkowicz A., Warszawa.

Manovich L., 2006, Jesylk nowych mediów, przeł. Cypryański P., Warszawa.

Maslow, A. H., 1986, W strone psychologii istnienia, przel. Wyrzykowska I., Warszawa.

Miłosz C.,1980, Rodrinna Europa, Paryż.

Miłosz C.,1980, Zniewolony umysł, Paryż.

Mrożek S, 2008, Emigranci, Warszawa.

Pamuk O., 2003, Stambut. Wspomnienia i miasto, przeł. Polat A., Kraków. 
Pismo Święte Starego i Nowego Testamentu, 1971, oprac. Zespół Biblistów Polskich, wyd. II poprawione, przekł. z jęz. oryg., Poznań - Warszawa.

Sandauer A., 1981, Studia teoretyczne, w: Kakiet M., red., Zebrane pisma krytyczne, t. 2, Warszawa. Tanpinar A.H., 2013, Spokojny umyst, przeł. Madejski R., Katowice.

\section{Netografia}

Christodoulou H., Cambridge E., Duggan J., Migrant 'Mass Murder' Essex lorry deaths - Driver 'passed out' when he opened door 'to get paperwork' and found bodies of 39 Chinese migrants, https:/ / www.thesun.co.uk/news/10174799/essex-lorry-bodies-driver-news-chinesearrest/?utm_m edium $=$ Social\&utm_campaign $=$ sunmaintwitter\&utm_source $=$ Twitter\#Echobox $=157190$ 9665 [dostęp: 08.11.2019].

For snoen faller, https://www.filmweb.no/skolekino/incoming/article1089138.ece [dostęp: 08. 11.2019].

Hisham Zaman, https://www.filmweb.no/profil/article1146189.ece [dostęp: 08.11.2019].

Hisham Zaman Awards, https://www.imdb.com/name/nm2106742/awards?ref_=nm_awd [dostęp: 08.11.2019].

Marius Matzow Gulbrandsen, Everything will be ok, http://minside.nfi.no/96676/everything-willbe-ok [dostęp: 08.11.2019].

van Hoeij B., Letter to the King (Brev til Kongen): Goteborg Review, https://www.hollywoodrepor ter.com/review/letter-king-brev-til-kongen-676397 [dostęp: 08.11.2019].

Artur Jacek Jędrzejewicz - dr, Instytut Językoznawstwa i Literaturoznawstwa, Uniwersytet Przyrodniczo Humanistyczny w Siedlcach, Siedlce, Polska.

Doktoryzował się z literaturoznawstwa (Uniwersytet Łódzki, 2010). Ukończył reżyserię filmową (Uniwersytet Śląski, WRiTV im. K. Kieślowskiego, 2002). Sporadycznie realizuje filmy dokumentalne dla TVP. Bada zależności: literatura - film - kultura. Porównuje teksty kultury w relacji: (nie)świadomość zbiorowa - Autor jako antropologiczny fenomen. Najważniejsze publikacje: Luis Buñuel - Sacrum ukryte (Gdańsk 2013), Umieranie za życia - analityczna refleksja nad filmem „亡̇ycie jako śmiertelna choroba przenoszona drogą płciową" (Kraków 2015), Luis Buñuel. Paradoksy uduchowionego ateisty (Siedlce 2016), Przełom wieków w kinie. Czas w kulturze i edukacji (Siedlce 2018). Kontakt: artur.jedrzejewicz@uph.edu.pl 